\title{
Distribution System Network Reconfiguration by using Artificial Bee Colony Algorithm.
}

\author{
Dharani Hemanth Kumar ${ }^{1}$, P Suresh Babu ${ }^{2}$, M Padma Lalitha ${ }^{3}$ \\ ${ }^{1}$ M.Tech Student,${ }^{2}$ Asst. Professor, ${ }^{3}$ Professor,${ }^{1,2,3}$ Department of EEE, \\ Annamacharya Institute of Technology \& Sciences, Rajampet, Kadapa, Andhra Pradesh, India.
}

\begin{abstract}
This paper presents a new methodology using artificial bee's colony algorithm (ABC) in the radial distribution systems for the placement and size of Distributed Generators (DG). The ABC algorithm is a new population based meta heuristic approach exalted by intelligent foraging behavior of honey bee swarm. This paper presents a feeder reconfiguration problem with Distributed Generation to the distribution system. In the recent years the application of Distributed Generation (DG) has found increasing attention. Optimal reconfiguration needs selection of the best set of branches to be opened so that the resulting radial distribution system has improved voltage profile system and minimized power loss. The developed methodology is demonstrated by a radial distribution system with distributed generation. The study results show that the optimal on/off patterns of the switches can be identified which give the minimum power loss while respecting all the constraints.
\end{abstract}

Keywords: Network reconfiguration, Loss reduction, Distributed generation, Artificial Bee Colony Algorithm.

\section{Introduction:}

Distribution systems are normally configured radially for efficient coordination of their protective devices [1]. Two types of switches are generally found in the system for both protection and configuration management. These are sectionalizing switches which are normally closed switches and tie switches which are normally opened switches [2]. The configuration of distribution system is varied, and loads are transferred among the feeders while the radial configuration format of electrical supply is still maintained By changing the positions of the sectionalizing and tie switches. This execution is known as feeder reconfiguration. The advantages obtained from feeder reconfiguration are real power loss reduction, balancing system load, bus voltage profile improvement, increasing system security and reliability, and power quality improvement [3-4] Etc.

Distribution systems have seen a significant increase in small-scaled generators, which is known as distributed generation (DG) over the last decade. Distributed generation are grid-connected or stand-alone electric generation units situated within the distribution system at or near the end user. Recent developments in DG technologies such as wind, solar, fuel cells, hydrogen, and biomass has drawn an attention for utilities to accommodate DG units in their systems. As the penetration of distributed generation is awaited to increase significantly in the near future, operation and planning of distribution networks may be necessary if this generation is to be integrated in a cost-effective manner [5], a paradigm shift in control. Such a conversion enables the system operator to maximize the use of the existing circuits by taking full advantage of generator dispatch, voltage regulators, control of transformer taps, reactive power management and system reconfiguration in an integrated manner.

One of the first papers on reconfiguration was presented by Merlin and Back [5]. Civanlar et al. introduced a simple innovative method for calculating the loss through the network reconfiguration [6]. The use of the power flow method based on a heuristic algorithm to determine the minimum loss configuration for radial distribution networks [7] was presented by Shirmohammadi and Hong. Baran and Wu modeled the problem of loss reduction and load balancing as an integer programming problem [8]. Nara et al. have presented an implementation using a genetic algorithm to look for the minimum loss configuration [9]. Goswami and Basu introduced a power-flow-minimum heuristic algorithm for distribution feeder reconfiguration [10]. Vanderson Gomes et al. proposed a heuristic strategy for reconfiguration of distribution systems [11].Lopez presented an approach for online reconfiguration [12]. Das proposed a fuzzy multi-objective approach to solve the network reconfiguration problem [13]. Olamaei et al. proposed a cost based on compensation methodology for distribution feeder reconfiguration considering distributed generators [14]. Niknam et al. presented an efficient multi-objective modified shuffled frog leaping algorithm that has been used to solve MDFR problem [15]. R.S rao et al proposed a harmony search algorithm for distributor reconfiguration [16]. J. Olamaei et al. presented a modified honey bee mating optimization algorithm for distribution feeder reconfiguration for loss Minimization with distributed generations [17]. In this paper, an Artificial Bee Colony (ABC) algorithm is used to solve a radial feeder reconfiguration with DG to reduce system loss in the distribution network. Minimizing the total 
system losses without violating operation constraints and maintaining the radial structure. The rest of this paper is organized as follows: Section 2 gives the problem formulation, Section 3 gives the overview of proposed $\mathrm{ABC}$ algorithm, Section 4 presents simulation results, and Section 5 concludes this paper.

\section{Problem Formulation:}

The objective of the optimal feeder reconfiguration problem is to minimize the total power loss as: Minimize $\mathrm{L}=\sum_{t=1}^{N l} \sum_{k=1}^{l}\left|I_{k}\right|^{2} R_{k}$ where $L=$ total power loss

$\mathrm{Nl}=$ number of load levels

$l \quad=$ number of feeders

$I_{k} \quad=$ current flow in branch $k$

$R_{K}=$ resistance of branch $k$

The objective function in (1) is subject to the

following constraints.

1) Power flow equations:

$$
\begin{array}{cl}
\mathrm{P}_{\mathrm{i}}=\sum_{j=1}^{N b}\left|Y_{i j} V_{i} V_{j}\right| \cos \left(\theta_{i j}+\delta_{j}-\delta_{i}\right) & \ldots \text { (2) } \\
\mathrm{Q}_{\mathrm{i}}=-\sum_{j=1}^{N b}\left|Y_{i j} V_{i} V_{j}\right| \sin \left(\theta_{i j}+\delta_{j}-\delta_{i}\right) & \ldots(3) \\
\text { where } P_{i}, Q_{i} & =\text { active and reactive power at } \\
N_{b} & =\text { number of buses } \\
Y_{i j} & =\text { element }(i, j) \text { in bus admittance } \\
V_{i}, V_{j} & =\text { voltage of bus } i \text { and bus } j \\
\Theta_{i j} & =\text { angle of } Y i j \\
\delta_{i}, \delta_{j} & =\text { voltage angle of bus } i \text { and } j
\end{array}
$$

bus $i$

2) Bus voltage limits:

$$
\mathrm{V}^{\min } \leq \mathrm{V}_{\mathrm{i}} \leq \mathrm{V}^{\max }
$$

3) Feeder capability limits:

$$
\left|\mathrm{I}_{\mathrm{k}}\right| \leq \mathrm{I}_{\mathrm{k}}{ }^{\max } \mathrm{k} €\{1,2,3 \ldots l\}
$$

4) Radial configuration format

5) No load-point interruption

$$
\text { where } \begin{aligned}
V^{\min } & =\text { minimum voltage } \\
V^{\max } & =\text { maximum voltage } \\
I_{\mathrm{k}}{ }^{\max } & =\text { maximum current capability of } \\
& \text { branch } k
\end{aligned}
$$

\section{Overview Of Artificial Bee Colony Algorithm (Abc):}

In the $\mathrm{ABC}$ algorithm, the colony of artificial bees contains three groups of bees: onlookers, employed bees and scouts. A bee going to the food source visited by it previously is named an employed bee and a bee waiting on the dance area for making decision to choose a food source is called an onlooker. A bee carrying out random search is called a scout. In the $\mathrm{ABC}$ algorithm, first half of the colony consists of employed artificial bees and the second half constitutes the onlookers. For each and every food source, there is only one employed bee. The employed bee whose food source is exhausted by the employed and onlooker bees becomes a scout. In the $\mathrm{ABC}$ algorithm, each cycle of the search consists of three steps: sending the employed bees onto the food sources and then measuring their nectar amounts selecting of the food sources by the onlookers after sharing the information of employed bees and determining the nectar amount of the foods; determining the scout bees and then sending them onto possible food sources. At the initialization stage, a set of food source positions are randomly selected by the bees and their nectar amounts are determined. Then, these bees come into the hive and share the nectar information of the sources with the bees waiting on the dance area within the hive. At the second stage, after sharing the information, every employed bee goes to the food source area visited by her at the previous cycle since that food source exists in her memory, and then chooses a new food source by means of visual information in the neighborhood of the present one. At the third stage, an onlooker prefers a food source area depending on the nectar information distributed by the employed bees on the dance area. As the nectar amount of a food source increases, the probability with which that food source is chosen by an onlooker increases, too. Hence, the dance of employed bees carrying higher nectar recruits the onlookers for the food 
source areas with higher nectar amount. After arriving at the selected area, she chooses a new food source in the neighborhood of the one in the memory depending on visual information. Visual information is based on the comparison of food source positions. When the nectar of a food source is abandoned by the bees, a new food source is randomly determined by a scout bee and replaced with the abandoned one. In our model, at each cycle at most one scout goes outside for searching a new food source and the number of employed and onlooker bees were equal. The probability $P_{i}$ of selecting a food source $i$ is determined using the following expression:

$$
\mathrm{P}_{\mathrm{i}}=\frac{f_{i}}{\sum_{n=1}^{s n} f_{n}}
$$

Where $f_{i}$ is the fitness value of the solution $i$ evaluated by its employed bee, which is proportional to the nectar amount of the food source in the position $i$ and $\mathrm{Sn}$ is the number of food sources which is equal to the number of employed bees (BN). Clearly, with this scheme good food sources will get more onlookers than the bad ones. After all onlookers have selected their food sources, each of them determines a food source in the neighborhood of his chosen food source and computes its fitness. The best food source among all the neighboring food sources determined by the onlookers associated with a particular food source $i$ and food source $i$ itself, will be the new location of the food source $i$. If a solution represented by a particular food source does not improve for a predetermined number of iterations then that food source is abandoned by its associated employed bee and it becomes a scout, i.e., it will search for a new food source randomly. This tantamount to assigning a randomly generated food source (solution) to this scout and changing its status again from scout to employed. After the new location of each food source is determined, another iteration of ABC algorithm begins. The whole process is repeated again and again till the termination condition is satisfied.

The food source in the neighborhood of a particular food source is determined by altering the value of one randomly chosen solution parameter and keeping other parameters

unchanged. This is done by adding to the current value of the chosen parameter the product of a uniform variety in $[-1,1]$ and the difference in values of this parameter for this food source and some other randomly chosen food source. Formally, suppose each solution consists of $d$ parameters and let $x_{i}=\left(x_{i 1}, x_{i 2}, \ldots ., x_{i d}\right)$ be a solution with parameter values $x_{i 1}, x_{i 2}, \ldots ., x_{i d}$. In order to determine a solution $\mathrm{v}_{\mathrm{i}}$ in the neighborhood of $\mathrm{x}_{\mathrm{i}}$, a solution parameter $\mathrm{j}$ and another solution $x_{k}=\left(x_{k 1}, x_{k 2}, \ldots ., x_{k d}\right)$ are selected randomly. Except for the value of the selected parameter $\mathrm{j}$, all other parameter values of $\mathrm{v}_{\mathrm{i}}$ are same as $x i$, i.e., $\left.v_{i}=\left(x_{i l}, x_{i 2}, \ldots ., x_{i(j-1),} x_{i j}, x_{i(j+1)}, \ldots ., x_{i d}\right)\right)$. The value $\mathrm{v}_{\mathrm{i}}$ of the selected parameter $\mathrm{j}$ in $\mathrm{v}_{\mathrm{i}}$ is determined using the following formula:

$$
\mathrm{v}_{\mathrm{ij}}=\mathrm{x}_{\mathrm{ij}}+\mathrm{u}\left(\mathrm{x}_{\mathrm{ij}}-\mathrm{x}_{\mathrm{kj}}\right)
$$

where $u$ is an uniform variate in $[-1,1]$. If the resulting value falls outside the acceptable range for parameter $j$, it is set to the corresponding extreme value in that range.

\section{Abc Algorithm For Netwok}

\section{RECONFIGURATION PROBLEM:}

The proposed artificial bee colony algorithm is summarized as follows:

1. Read the line input data; Initialize MNC (Maximum Iteration Count) and base case as the best solution.

2. Construct initial Bee population (solution) $x i j$ as each bee is formed by the open switches in the configuration and the number of employed bees are equal to onlooker bees.

3. Evaluate fitness value for each employed bee by using the following the formula.

4. Initialize cycle $=1$

$$
\text { fitness }=\frac{1}{1+\text { powerloss }}
$$

5. Generate new population (solution) vij in the neighborhood of $x i j$ for employed bees using equation (7) and evaluate them

6. Apply the greedy selection process between $x i$ and $v i$

7. Calculate the probability values $P i$ for the solutions $x i$ by means of their fitness values using the equation (6)

8. Produce the new populations $v i$ for the onlookers from the populations $x i$, selected depending on $P i$ by applying roulette wheel selection process, and evaluate them

9. Apply the greedy selection process for the onlookers between $x i$ and $v i$

10. Determine the abandoned solution, if exists, and replace it with a new randomly produced solution $x i$ for the scout bees using the following equation.

$$
\mathrm{x}_{\mathrm{ij}}=\min _{\mathrm{j}}+\operatorname{rand}(0,1) *\left(\max _{\mathrm{j}}-\min _{\mathrm{j}}\right)
$$

11. Memorize the best solution achieved so far.

12. cycle $=$ cycle +1

13. if cycle $<\mathrm{MIC}$, go to step 5, otherwise go to step 14

14. Stop. 


\section{Test Results:}

The proposed method was tested on 33-busradial distribution system and results have been obtained to evaluate its effectiveness. In this system, the substation voltage is considered as 1.0 p.u. and all the tie and sectionalizing switches are considered as candidate switches for reconfiguration problem. The algorithm of this method was programmed in MATLAB environment and run on a intel core i5, $3.3 \mathrm{GHz}$ personal computer with 2 GB RAM.

Four cases are considered for this proposed method as follows:

Case-1:The feeder is without Reconfiguration and without distributed generation.

The initial power loss in this system is $203.2 \mathrm{kw}$.

\begin{tabular}{|l|l|l|l|l|}
\hline & Case 1 & Case 2 & Case 3 & Case 4 \\
\hline $\begin{array}{l}\text { Sectionalizing } \\
\text { switches to be } \\
\text { open }\end{array}$ & -- & $\begin{array}{l}7,24,9, \\
31,13\end{array}$ & -- & $\begin{array}{l}6,24,11, \\
29,12\end{array}$ \\
\hline $\begin{array}{l}\text { Tie switches to } \\
\text { be closed }\end{array}$ & -- & $33,34,35$, & -- & $33,34,35$, \\
\hline $\begin{array}{l}\text { Total power } \\
\text { loss (KW) }\end{array}$ & 203.2 & 102.9 & 119.50 & 51 \\
\hline $\begin{array}{l}\text { Percentage } \\
\text { reduction of } \\
\text { loss }\end{array}$ & -- & 49.30 & 41.07 & 74.88 \\
\hline
\end{tabular}

Case-2:The feeder is with reconfiguration and without distributed generation.

In this case the losses are reduced to $102.9 \mathrm{kw}$ by opening the sectionalizing switches at 7, 24, 9, 31, 13 and closing the $33,34,35,36,37$ tie switches.

Case-3: The feeder is without reconfiguration and with distributed generation.

Here the optimum size of DG is placed at bus 6 on the existing system with $2545.5 \mathrm{~kW}$. By optimally placing the DG the losses are reduced to $119.50 \mathrm{kw}$. In this case the losses that are reduced when compared to original system are $41.07 \%$.

Case-4: The feeder is with reconfiguration and distributed generation.

In this case reconfiguration and DG Placing has done simultaneously so that the reduction in losses is achieved with minimizing it to $51 \mathrm{kw}$ which is $74.88 \%$ lesser than original system.

\section{Conclusions}

In this paper, a new population based Artificial Bee colony Algorithm (ABC) has been proposed to solve the network reconfiguration problem in a 33-bus radial distribution system. The main objectives considered in the present problem are minimization of real power loss, voltage profile improvement and feeder load balancing subject to the radial network structure in which all loads must be energized. It can be observed that $74.88 \%$ of loss reduction can be achieved by the case4 is the simultaneous solution of feeder reconfiguration and DG placement comparing with other cases by the $\mathrm{ABC}$ method in the system. The results shows that the Artificial Bee Colony $(\mathrm{ABC})$ algorithm for real power loss minimization to be the most effective and efficient

\section{References:}

[1]. Baran, M .E. and Wu, F.F, "Network reconfiguration in distribution systems for loss reduction and load balancing," IEEE Trans. Power Deliv., 1989, Vol. 4, No. 2, pp. 1401-1407.

[2]. Kashem, M.A., Ganapathy, V. and Jasman, G.B. "Network reconfiguration for enhanceme nt of voltage stability in distribution networks," IEE Proc. C-Genes. Transm. Distrib., 2000, pp. 171 -175.

[3]. Ackermann T., Andersson G., Soder L., "Distributed generation: a definition," Electric Power Systems Research, 2001, Vol. 57, no.3 pp. 195-204.

[4]. Chiradejaand P., and Ramakumar R ., "An approach to quantify the technical benefits of distributed generation," IEEE Trans. Energy Convers., 2004, Vol.19, no .4, pp. 764-773. 
[5]. Merlin, A. and H. Back, "Search for a minimal-loss operating spanning tree configuration in an urban power distribution system," Proc. 5th Power System Computation Conf.,1975, Cambridge (U.K.): pp. 1-18.

[6]. Civanlar, S., J.J. Grainger, H. Yin and S.S.H. Lee, "Distribution feeder reconfiguration for loss reduction," IEEE Transactions on Power Delivery, 1988, No 3: pp. 1217-1223.

[7]. Shirmohammadi, D. and H.W. Hong, "Reconfiguration of electric distribution networks for resistive line loss reduction," IEEE Tran sactions on Power Systems, 1989, Vol.4: pp. 1492-1498.

[8]. Baran, M.E. and F.F. Wu, "Network reconfiguration in distribution systems for loss reduction and load balancing". IEEE Transactions on Power Delivery," 1989, Vol.4, pp.1401-1407.

[9]. Nara, K., A. Shiose, M. Kitagawoa and T. Ishihara, "Implementation of genetic algorithm for distribution systems loss minimum reconfiguration,” IEEE Trans. Power Syst.,1992, Vol.7, pp.1044-1051.

[10]. Goswami, S.K. and S.K. Basu, "A new algorithm for the reconfiguration of distribution feeders for loss minimization," IEEE Transactions on Power Delivery, 1992, Vol.7, pp.1484-1491.

[11]. Vanderson Gomes, F., S. Carneiro, J.L.R. Pereira, Garcia Mpvpan, and L. Ramos Araujo "A new heuristic reconfiguration algorithm for large distribution systems," IEEE Transactions on Power systems, 2005, Vol.20, pp.1373-1378.

[12]. Lopez, E.h., "Opaso Online reconfiguration considering variability demand: Applications to real networks," IEEE Transactions on Power Systems, 2004, Vol.19, pp. 549-553.

[13]. Das, D., "A fuzzy multi-objective approaches for network reconfiguration of distribution systems," IEEE Transactions on Power Delivery, 2006, 21(1): 202-209.

[14]. Olamaei, J., T. Niknam and G. Gharehpetian, "An approach based on ant colony optimization for distribution feeder reconfiguration considering distributed generators," 19th International Conference on Electricity Distribution, Vienna, 2007.

[15]. Niknam, T., and E. Azad Farsani, "A hybrid self-adaptive particle swarm optimization and modified shuffled frog leaping algorithm for distribution feeder reconfiguration," Engineering Applications of Artificial Intelligence., 2010.

[16]. R.S Rao, S.V.L Narasimham, M.R Raju and A.S Rao, "Optimal network reconfiguration of large scale distribution system using harmony search algorithem," IEEE transactions on power systems,2011, Vol.26 ,No.3, pp.1080-1088.

[17]. Javad Olamaei, Sirous badali and Taher Niknam, "Distribution Feeder Reconfiguration for Loss Minimization Based on Modified Honey Bee Mating Optimization Algorithm with Distributed Generations," Australian Journal of Basic and Applied Sciences, 2012, Vol.6, pp.133-141. 